\title{
Methodology development of human task simulation as PLM solution related to OCRA ergonomic analysis
}

\author{
M. Annarumma ${ }^{1}$, M. Pappalardo ${ }^{2}$, and A. Naddeo $^{3}$ \\ ${ }^{1}$ University of Salerno, Fisciano (SA), Italy, maannarumma@unisa.it \\ ${ }^{2}$ University of Salerno, Fisciano (SA), Italy, mpappalardo@unisa.it \\ ${ }^{3}$ University of Salerno, Fisciano (SA), Italy, anaddeo@unisa.it
}

\begin{abstract}
In the current demanding global marketplace, ensuring that human fit, form and function are comprehensively addressed, is becoming an increasingly important aspect of design and, in particular, obliges the most important automotive industries to develop more flexible assembly lines and better methods for PLM solution. In the meantime, designers attempt to elaborate product development methodologies that conform health and safety standards while still maximizing the productivity. The aim of this work consists in developing a methodology based on preventive ergonomics and feasibility analyses of assembly tasks, simulating a work cell, in which acts a digital human model (manikin), in order to maximize human safety and performance and analyze manikin interaction in the virtual environment. In ergonomic analyses the OCRA protocol will be used, evaluating different involvement degrees of upper limb segments. The methodology is carried out by ergonomic tool of DELMIA software, using Digital Human Models technology.
\end{abstract}

Keywords: PLM solution, ergonomic analysis, OCRA protocol, Digital Human Models

\section{Introduction}

The actual manufacturing processes are designed in order to produce a given good but, often, have a limited flexibility, in particular from the point of view of ability to meet meaningful variations of productivity in rapid way and result being equal. The products increasing proliferation and the need to fit in real time the manufacturing on variations of volumes required by the market (without resorting to hard-working actions for rearrangements of men, means and materials, with heavy impact on costs, process stability, quality) represents a competitiveness decisive factor. 
In fact, each product variation can imply changes that become: different and more flexible working place organizations, different assembly procedures, different methods and tools to be used in operations and even different tasks subdivisions among the workers in the working places.

The manufacturing process planning is fundamental [1], since it allows to define and to verify product assembly sequences [2], to create the assembly line layout, to assign the time needed for each operation, to verify lines performances also in terms of productivity and use of the resources, to carry out the lines balancing and to analyze production costs.

In order to assist the manufacturing process planning, studies and software tools was developed, allowing the whole manufacturing process simulation with Virtual Manufacturing techniques [3] (DELMIA, VIS FACTORY, UGS, etc).

Subsequently, verifying new types of accidents or work diseases, it realizes the importance of the working place ergonomics [4], [5] considered as "respect of the ergonomic principles in the working place conception, in the tools choice and in the definition of work and production methods, also in order to attenuate the monotonous and repetitive work".

For this reason, there was the need to introduce in virtual environments biomechanical digital models able to simulate the man from a cinematic and dynamic point of view [6].

Since the ' 70 years many studies were addressed to the biomechanical models development. The first notable results were gotten by Chow and Jacobson (1971), which developed a theory for the human movements optimal control; Seireg and Arvikar (1975), whose results were taken by Rohrle (1984), studied the optimal distribution problem of the muscular strength in the hip, knee and ankle articulations during the walking; Marshall (1986) developed optimization criterions for the mass centre trajectory computation; Bean, Chaffin and Schultz (1988) proposed a linear programming method for the muscular strengths computation in a muscular-skeletal system.

In the last years DHM (Digital Human Modelling) software has been developed, provided with digital biomechanical models, for instance Jack (UGS), Ramsis (TechMat) and Delmia (Dassault Systemes) [7], which allow to simulate human movements by specific tools.

By these softwares it is possible to create specific virtual environments with CAD data available, in which to insert the manikins; in such way the operator can be simulated during the productive task carrying out in his working place. This approach allows effecting all the necessary analyses before the productive line realization, reducing both design variation costs and execution times. 


\section{Description of the approach to development methodology}

The approach followed for developing this methodology is based on the Virtual Manufacturing technologies. These tools allow to reach totally virtual factory, constituted by virtual models of men, tools and materials, that can be analyzed their continuous interactions. The virtual tools seem the ideal environment to solve the problems related to manufacturing high variability/flexibility, since they allow, if opportunely developed, to study changes needed for the line organization, in order to reach optimal operating solutions.

The developments needed to reach the target concern, in particular, the "integrated" methodologies availability for the virtual simulation and the Working Place "Ability" optimization, considering the whole of factors that affect the whole working place performances: man, means of work, material handling, safety and ergonomics.

In order to achieve this goal a preliminary work of a virtual work-cell reproduction was carried-out. This means to collect product and process CAD models by the Product Data Management (PDM) and to arrange them according to the real lay-out and situation which will be effectively reproduced into the plant. Tools and methods typically used in computer graphics applications must be applied on the CAD models in order to have a realistic simulation.

Subsequently, several factors that characterize product process performances was integrated, both in terms of productivity, machineries and manpower output, both in terms of ergonomic analyses on human factors as: postures, movements, cinematic potentiality of the human body, efforts feasibility, tools accessibility, breaks management within the work shift and additional factors that take into account working environment characteristics.

The whole of these factors, opportunely weighed according to examined context characteristics, can be used as assessment and designing procedure of working configurations.

Using Virtual Engineering, the need to evaluate human factors (HF) in real life, forces the introduction of virtual manikins in virtual environments already carried out for product and process prototypes, and that has developed the "Digital Human Modelling" (DHM) [8-9-10]. These human models are digital biomechanical models, able to simulate the man from a cinematic and dynamic point of view.

\subsection{Aims of the work}

The aim of this work consists in developing a design methodology founded on ergonomics and feasibility preventive analyses of work tasks, by simulating a work-cell, in which acts a digital human model. 
Combining process and ergonomic analyses and analyzing the relationship between workers and other entities within the simulation, with the evaluation of manikin interaction in the virtual environment, thanks to Digital Human Models (DHM) technology, it possible to improve product development process and maximize human safety and performance in designing step.

OCRA (OCcupational Repetitive Actions) protocol was used in ergonomic analyses; OCRA's index consider time and posture factors, in order to evaluate different involvement degrees of human upper limbs.

The OCRA index is the ratio between the Actual number of Technical Actions carried out during the work shift (ATA) and the Reference number of Technical Actions (RTA) (for each upper limb) which is specifically determined in the examined scenario.

Subsequently, an analysis of postures (the type of quantitative and qualitative joint involvement, the static or dynamic component of movement) will make it possible to obtain a general estimation of the degree of repetitiveness and of the duration of single joint movements within the sequence of technical actions.

\begin{tabular}{|c|c|c|c|c|c|c|c|c|c|}
\hline SHIFT DURATION & 480 & & & & Toek A: : & & & & \\
\hline Breaks (min) & so & & & & Toek B: & & & & \\
\hline Non repetitive work time (min) & 15 & & & & Toek c: & & & & \\
\hline Work time considered as recovery (min) & 0 & & & & Toek D: & & & & \\
\hline \multirow[t]{4}{*}{ Total repetitive vork net time in the shift } & 435 & & & & & & & & \\
\hline & & & & & & & & & \\
\hline & A & E & c & D & & A & B & c & D \\
\hline & $100 \%$ & & & & & $100 \%$ & & & \\
\hline Repetitive work net time for each task & 435 & 0 & 0 & 0 & & & & & \\
\hline No. of units per shift & 5220 & & & & & & & & \\
\hline No.hours without recovery period & 5 & & & & & & & & \\
\hline Recovery multiplier (Rich] & 0,45 & & & & & & & & \\
\hline ACTION FREQUENCY CONSTANT & 30 & & & & & & & & \\
\hline RIGHT & A & B & c & $D$ & LEFT & A & B & $\mathrm{c}$ & $D$ \\
\hline Force multiplier (FOM & 0,94 & & & & Foroe multiplier $\left(\mathrm{FOMH}_{\mathrm{H}}\right]$ & 0,92 & & & \\
\hline Posture multiplier (POH) & 0,60 & & & & Posture multiplier (POM) & 0.70 & & & \\
\hline Âdditional multiplier $\left(\hat{A}_{\mathrm{d}} \mathrm{A}\right)$ & 0,85 & & & & Additional mulkiplier $\left(\hat{A} d_{m}\right)$ & 0,85 & & & \\
\hline Repetitiveness multiplier (Reien] & 0,70 & & & & Repetitiveness multiplier (Reien) & 0,70 & & & \\
\hline Reference No. Of techical actions without Rion & 4379 & & & & Reference No. Of techical actions without RicH & 5011 & & & \\
\hline CYCLE TIME (sec.) & 5.0 & solyo! & solyo! & soivio: & CYCLE TIME (sec.) & 5.0 & solvio! & solyo: & solvio! \\
\hline TOT.NO.OF TECHNICAL ACTIONS OESERVED in each tosk & 10440 & \#DIVIO! & \begin{tabular}{|l|} 
\#DIV10! \\
\end{tabular} & \#DIVio! & TOT.NO.OF TECHNICAL ACTIONS OBSERVED in esch to. & 10440 & \#DIVio! & \#DIV10! & \#DIVIO! \\
\hline frequency (No.of technical actions per mint & 24 & sDivio! & solyo! & soivio! & frequency (No.of technical actions per mil & 24 & solyio! & soivio! & solyio! \\
\hline No. of technical actions in the cycle & 2,0 & 0,0 & 60,0 & 0 & No. of technical actions in the cycle & 2,0 & 0,0 & 0,0 & 0 \\
\hline TOT.NO.OF ACTUAL TECHNICAL ACTIONS (ATA) & 10440 & & & & TOT.NO.OF ACTUAL TECHNICAL ACTIONS (ATA) & 10440 & & & \\
\hline TOT.NO.OF. RECOMMENDED TECHNICALLACTIONS (RT) & 1971 & & & & TOT.NO.OF. RECOMMENDED TECHNICAL ACTIONS (F & 2255 & & & \\
\hline Duration multiplier (Dum). & 1,0 & & & & Duration multiplier (DuH). & 1,0 & & & \\
\hline \multirow{2}{*}{ OCRA INDEX RIGHT } & 5.3 & & & & OCRA INDEX LEFT & 4.6 & & & \\
\hline & & & & & & & & & \\
\hline \multirow{2}{*}{ Forecast of VMSDs } & & & & & & & & & \\
\hline & $\begin{array}{l}\text { mis } \\
11,4\end{array}$ & $\begin{array}{c}\text { AVERAGE } \\
12.7\end{array}$ & $\begin{array}{l}m a x \\
13,9\end{array}$ & & Forecast of VMSDs & $\min _{10,0}$ & $\begin{array}{l}\text { AVERAGE } \\
11,1\end{array}$ & $\begin{array}{l}-2 x \\
12,1\end{array}$ & \\
\hline & & & & & & & & & \\
\hline da $0 a 2,2$ & & & & & & & & \\
\hline da $2,3,3,3,5$ & \multirow{3}{*}{\multicolumn{2}{|c|}{$\begin{array}{l}\text { VERY LOW } \\
\text { PPESENT } \\
\text { HIGH }\end{array}$}} & & & & & & & \\
\hline & & & & & & & & & \\
\hline oltre 9 & & & & & & & & & \\
\hline
\end{tabular}

Figure 1: OCRA ergonomic evaluation tool 


\begin{tabular}{|c|c|c|c|c|}
\hline SHIFT DURATIOH & 480 & & & \\
\hline Breaks (min) & 30 & & & \\
\hline Non repetitive work time (min) & 15 & & & \\
\hline Work time considered as recovery (min) & 0 & & & \\
\hline \multirow[t]{3}{*}{ Total repetitive york net time in the shift } & 435 & & & \\
\hline & A & $\mathrm{B}$ & $\mathrm{c}$ & D \\
\hline & $100 \%$ & & & \\
\hline Repetitive work net time for each task & 435 & 0 & 0 & 0 \\
\hline No. of units per shift & 5220 & & & \\
\hline No.hours without recovery period & 5 & & & \\
\hline Recovery multiplier $\left(\mathrm{Rc}_{\mathrm{H}}\right)$ & 0,45 & & & \\
\hline ACTION FREQUENCY CONSTANT & 30 & & & \\
\hline
\end{tabular}

Figure 2: OCRA ergonomic evaluation tool zoom top

\begin{tabular}{|c|c|c|c|c|}
\hline LEFT & $A$ & $\mathrm{~B}$ & $\mathrm{c}$ & D \\
\hline Force multiplier ( $\left.\mathrm{FO}_{\mathrm{H}}\right)$ & 0,92 & & & \\
\hline Posture multiplier $\left(\mathrm{PO}_{\mathrm{H}}\right)$ & 0,70 & & & \\
\hline Additional multiplier $\left(A d_{H}\right)$ & 0.85 & & & \\
\hline Repetitiveness multiplier $\left(\mathrm{Re}_{\mathrm{H}}\right)$ & 0,70 & & & \\
\hline Reference No. Of techical actions without $R c_{H}$ & 5011 & & & \\
\hline CYCLE TIME [sec.] & 5.0 & EDIYio! & EDIYIO! & sDIYio! \\
\hline TOT.NO.OF TECHNICAL ACTIONS OBSERVED in esch to: & 10440 & \#DIVio! & \#DIV10! & \#DIVio! \\
\hline frequency (No.of technical actions per mir & 24 & EDIYio! & EDIYIo! & EDIYio! \\
\hline No. of technical actions in the cycle & 2,0 & 0,0 & 0,0 & 0 \\
\hline TOT.NO.OF ACTUAL TECHNICAL ACTIONS (ATA) & 10440 & & & \\
\hline TOT.NO.OF. RECOMMENDED TECHNICAL ACTIONS (R & 2255 & & & \\
\hline Duration multiplier (DUM). & 1,0 & & & \\
\hline OG.RA INLEEX LEFT & 4.6 & & & \\
\hline Forecast of MMSDs & min & AYERAGE & $=3 x$ & \\
\hline & 10,0 & 11.1 & 12.1 & \\
\hline
\end{tabular}

Figure 3: OCRA ergonomic evaluation tool zoom right 


\begin{tabular}{|c|c|c|c|c|}
\hline RIGHT & $A$ & $\mathrm{~B}$ & $\mathrm{c}$ & $\mathrm{D}$ \\
\hline Force multiplier $\left(\mathrm{Fo}_{\mathrm{H}}\right)$ & 0,94 & & & \\
\hline Posture multiplier ( $\mathrm{POO}_{\mathrm{H}}$ ) & 0,60 & & & \\
\hline Additional multiplier $\left(\hat{A d}_{\mathcal{H}}\right)$ & 0,85 & & & \\
\hline Repetitiveness multiplier $\left(\mathrm{Re}_{\mathrm{H}}\right)$ & 0,70 & & & \\
\hline Reference No. Of techical actions without $\mathrm{Rc}_{\mathrm{H}}$ & 4379 & & & \\
\hline CYCLE TIME (sec.] & 5.0 & EDIYio! & EDIYIo! & EDIYio! \\
\hline TOT.NO.OF TECHNICAL ACTIONS OBSERVED in coch toek & 10440 & \#DIV/0! & \#DIVio! & \#DIVio! \\
\hline frequency (No.of technical actions per mint & 24 & EDIYio! & sDIYIo! & EDIYio! \\
\hline No. of technical actions in the cycle & 2,0 & 0,0 & 60,0 & 0 \\
\hline TOT.NO.OF ACTUAL TECHNICAL ACTIONS (ATA) & 10440 & & & \\
\hline TOT.NO.OF. RECOMMENDED TECHNICAL ACTIONS (RT; & 1971 & & & \\
\hline Duration multiplier ( $\mathrm{D} u_{\mathrm{H}}$ ). & 1,0 & & & \\
\hline OCRA INDEX RIGHT & 5.3 & & & \\
\hline Forecast of YMSDs & $\begin{array}{l}\text { min } \\
11,4 \\
\end{array}$ & $\begin{array}{c}\text { AYERAGE } \\
12.7 \\
\end{array}$ & $\begin{array}{l}3 x \\
13.9 \\
\end{array}$ & \\
\hline da 0 a 2,2 & \\
\hline da 2,3 a 3,5 & \multicolumn{4}{|c|}{ VERY LOW } \\
\hline da 3,6 a 9 & PRESENT & & & \\
\hline oltre 9 & HIGH & & & \\
\hline
\end{tabular}

Figure 4: OCRA ergonomic evaluation tool zoom

For these reasons, the methodology was developed integrating design/ simulation tools, which exactly allows simulating and analyzing the work environment with digital human models that carry out manual assembly tasks. In this way, designers are assisted and guided in the context of a product/service, before it exists and throughout its entire lifecycle.

Therefore, an ergonomic evaluation tool, based on the OCRA protocol, as shown in figures 1,2,3,4 has been implemented and integrated inside the DHM software used for carrying out the simulation, recognizing several human postures and making ergonomic assessments founded on other standard protocols, by own specific tools.

The tool gives a final validation of the task. Input data which can be acquired during the simulation are:

- $\quad$ numerical manikin body information (angles and postures);

- $\quad$ task and single movement times.

The Computer Aided Innovation consists in using both posture recognition and all ergonomic evaluation tools within a Product-Process-Resources (PPR) data 
collaboration system, that's ensuring that human factors become an intuitive component in the manufacturing design process, so having several advantages:

- to improve simulation reliability: experts are supported, in real time, during the simulation because they can define the best movement for the worker, cutting down or changing incongruous postures;

- to improve the analysis performance: according to analyzed task, the expert can evaluate the most meaningful index between all the available ones;

- to ensure conformance to relevant health and safety standards;

- to reduce analysis time: critical postures are recognized at once, reducing subjective interpretations;

- to accelerate time to market;

- to reduces design timeframe and associated costs.

This complete integration with PPR data system allows companies to share their best practices and ensure everyone has access to the right information at the right time, optimizing workplaces and work cell design and increasing productivity.

\subsection{Application on case study}

In order to validate the methodology, the work present an application of the method to an interesting case study, by a simulation of an assembly task inside the car-body, that suggests new solutions, carrying out a more ergonomic and efficient task.

First of all, the virtual work cell has been built, therefore 3D models of the car and the assembly line have been collected and merged.

Then, a digital human model has been put into the virtual environment simulating the assembly task, in order to evaluate the situation using the classical approach.

The ergonomic study has been conducted on an operator employed in an operation frequently carried out during the dashboard assembly inside the car's cabin.

In figure 5 is shown an axonometric sight of the virtual work place with the digital human model.

The manikin's movements have been evaluated and the most critical postures, as shown in figure 6, during the simulation have been analyzed with ergonomics indexes, above all with OCRA index. According to this kind of analysis, a different approach to the work place improves the user's comfort thanks to a more comfortable arms movements. 
In addition to analysis tools provided in Delmia software, a form for the OCRA index evaluation has been developed, integrated in the software and which can be recalled by the menu of Delmia tools, appearing to screen as a dialogue box, in which can be input data drawn by the simulation's observation, and allowing automatic assessment of the aforesaid ergonomic index.

It should be underlined that the OCRA index "critical values" and its association with the occurrence of Upper Limbs Work-related Musculo-Skeletal Disorders (UL-WMSDs), reported in figure 7, should be used as an help to better frame the risk assessment and more effectively guide any consequent preventative actions, rather than rigid numbers splitting results between "risk" or "no risk".

In our case (OCRA_dx $=0.9$, OCRA_sx $=0.6$ ), the dashboard assembly operation, under examination, represents a not very critical example from the ergonomic point of view: it doesn't require great strength, and upper limbs' postures are not at risk considerably. These factors, with a good organization of the work shift, allow to say that UL-WMSDs occupational diseases are not forecasted.

The innovation introduced by this tool, in comparison with the classical manual compilation of the form, consists in the followings advantages:

- the index evaluation is simplified by surveys of numerical data on manikin postures, avoiding uncertain situations and minimizing evaluation errors from the operator;

- $\quad$ automatic assignment of indicative values of risk situations, beginning from times of duration of critical postures.

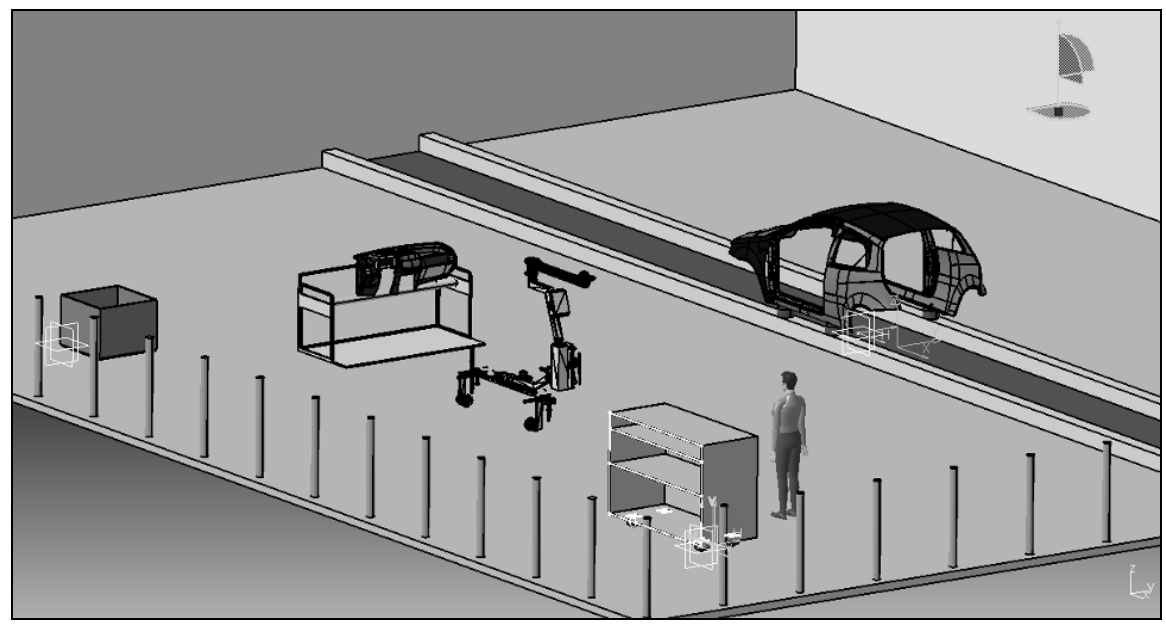

Figure 5: Assembly line 


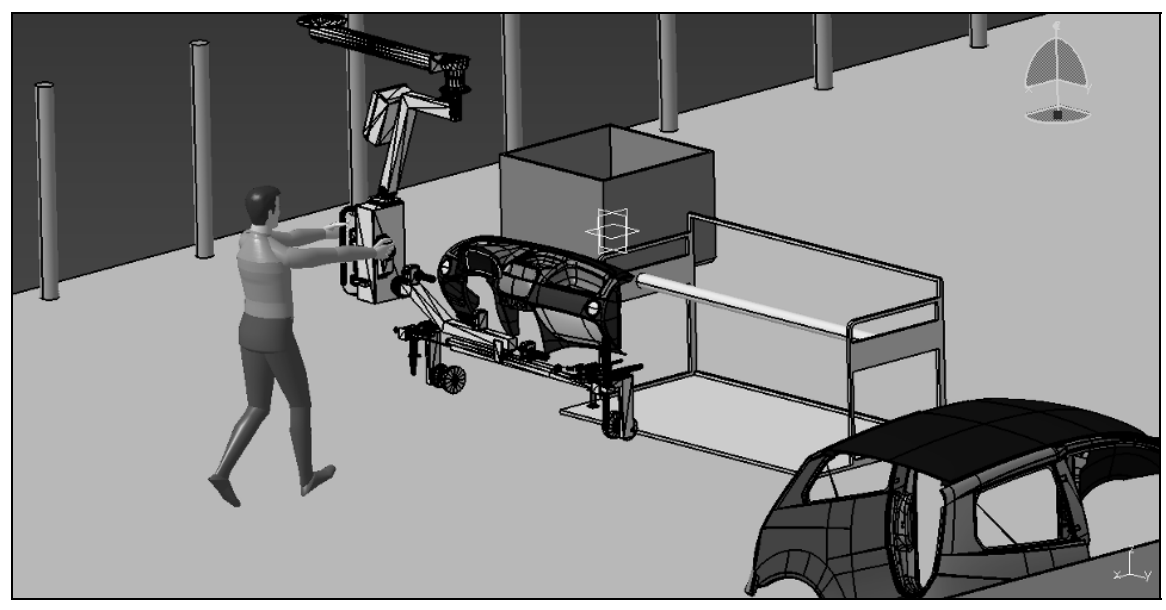

Figure 6: Critical posture

\begin{tabular}{|c|c|c|c|}
\hline AREA & OCRA INDEX VALUES & RISK LEVEL & CONSEQUENCES \\
\hline GREEN & $£ 2,2$ & $\begin{array}{l}\text { NO RISK (UL-MMSDS (PA) forecast is not } \\
\text { significantly different from the one expected in the } \\
\text { reference population). }\end{array}$ & Acceptable, no consequences. \\
\hline YELLOW & $2,3-3,5$ & $\begin{array}{l}\text { WERY LOW RISK (UL-MMSDS (PA) forecast is } \\
\text { higher than previous but lower than twice the one } \\
\text { expected in the reference population). }\end{array}$ & $\begin{array}{l}\text { Advisable to set up improvements with } \\
\text { regard to structural risk factors (posture, force, } \\
\text { technical actions, etc.) or to suggest other } \\
\text { organizational measures. }\end{array}$ \\
\hline RED & $>3,5$ & $\begin{array}{l}\text { RISK (UL-WMSDS (PA) forecast is higher than } \\
\text { twice the one expected in the reference } \\
\text { population. The higher the index, the higher the } \\
\text { risk). }\end{array}$ & $\begin{array}{l}\text { Redesign of tasks and workplaces according } \\
\text { to priorities is recornmended }\end{array}$ \\
\hline
\end{tabular}

Figure 7: OCRA Method: Final assessment criteria

\section{Conclusions}

Manufacturing organizations today continue to design and develop machines, vehicles and products that are capable of performing better, faster and longer. An increasingly design consideration is to ensure that these technological innovations are being designed from the perspective of people who actually build, maintain and operate them. Therefore, manufacturers must consider these human factors early in the product life cycle.

The power of this methodology is notable and its application could occur in any step of the product/process development. 
In addition to traditional tools of data analysis, this CAI methodology takes advantage of simulation tools of the product development process for Product Lifecycle Management (PLM) solutions and human factors evaluation tools, geared towards understanding and optimizing the relationship between humans and the products which they manufacture, install, operate and maintain. These tools take place as a link between the virtual product and the virtual factory, assuring a two-way communication between them.

The obtaining advantages are the following:

- to analyze the task feasibility in relation to operator anthropometric characteristics;

- to analyze the work place layout in relation to the task to carry out and to operator anthropometric characteristics;

- to store sequences of operations in a dedicated database, in order to make analyses in different steps of the product development process;

- to support the ergonomic indexes computation, in order to evaluate the risk due to Loads Manual Moving and Manual Assembly operations or to not comfortable postures;

- to carry out training phase on the ground of the optimised methods by the use of movies simulated and by the workers involvements in simulated tasks.

Using these analyses and evaluations it is possible to obtain indications for modifying the design in process development step.

Therefore this method allows a significant saving in terms of time and costs in design process, providing the enterprise with an important competitive lever.

\section{References}

1. Laring J., Christmansson M., Dukic T. et al.: Simulation for Manufacturing Engineering (ViPP), Digital Human Modelling for Design and Engineering Symposium, Iowa City (Iowa), 14-16 June (2005).

2. Miller D. M., Park Y.: Simulation and Analysis of an Automotive Assembly Operation, Southern Automotive Manfacturing Conference \& Exposition, Nashville (Tennessee), 11-13 August (1998).

3. DELMIA WORLD NEWS, Managing Change Across Virtual Design and Manufacturing, Delmia World News, n. 14 (2007).

4. Di Pardo M., Riccio A., Sessa F.: Intelligent Design of Ergonomic Workplace, CRF, ELASIS, Proceedings of IPMM, in The 6th International Conference on Intelligent Processing and Manufacturing of Materials, Salerno, 25-29 June (2007).

5. Temple R., Adams T.: Ergonomic Analysis of a Multi-Task Industrial Lifting Station Using the NIOSH Method. Journal of Industrial Technology, vol. 16(2), (2000).

6. Gu E. Y., Oriet L. P.: Proactive Ergonomic Verification Through Human Biodynamic Modeling and Digital Simulation, Southern Automotive Manufacturing Conference and Exposition Birmingham, Alabama, 28-30 September (1999).

7. http://www.delmia.com. 
8. Albers K. M., Abshire K. J.: Virtual Human Modeling for Manufacturing and Maintenance, in Digital Human Modeling for Design and Engineering Conference and Exposition, Dayton (Ohio), 28-29 April (1998).

9. Geyer M., Rösch B.: Human Modeling and e-Manufacturing, Digital Human Modeling for Design and Engineering Conference and Exposition, Arlington, Virginia, 26-28 June, (also SAE Paper n. 2001-01-2119) (2001).

10. Stephens A., Godin C.: The Truck that Jack Built: Digital Human Models and Their Role in the Design of Work Cells and Product Design, in Digital Human Modelling for Design and Engineering Conference, Lyon (France), 4-6 July (2006). 